\title{
Current Pharmacological and Emerging Non-Pharmacological Treatments in Slowing the Progression of Mild Cognitive Impairment: A Literature Review
}

\author{
Phoebe Thum, BSc Student [1]*, Damon Ye, BSc Student [1]
}

[1] Department of Biomedical Sciences, University of Guelph, Guelph, Ontario, Canada N1G 2W1

*Corresponding Author: pthum@uoguelph.ca

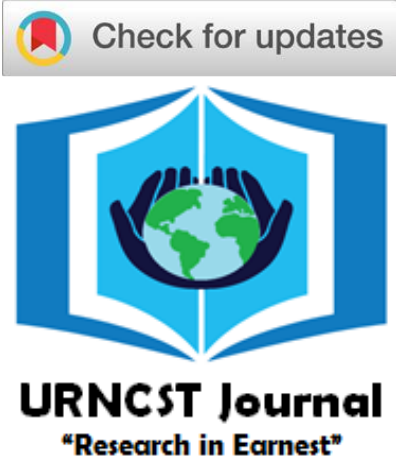

\begin{abstract}
Introduction: MCI is considered as a prodromal stage between normal cognitive aging and dementia given its potential to develop into various forms of dementia, most notably Alzheimer's disease (AD). This translates to a need for effective pharmacological and non-pharmacological treatments to prevent the progression of MCI and subsequently slowing AD onset. This review aims to discuss the effectiveness of pharmacological and non-pharmacological interventions in slowing MCI progression.

Methods: A literature search was conducted using the PubMed database for randomized controlled trials (RCTs) examining the effectiveness of interventions with individuals with MCI. Keywords included "mild cognitive impairment", "drug", "treatment", and "randomized controlled trials". Articles were evaluated on criteria relevant to the review's purpose.

Results: Studies on different pharmacological and non-pharmacological interventions demonstrated promising results in slowing the progression of MCI into dementia. Acetylcholinesterase inhibitors (AChEIs) display favourable results on multiple cognitive assessments when compared to placebo. Non-pharmacological interventions, such as diet supplementation or exercise, also have the potential in improving performance in a multitude of cognitive domains.

Discussion: In multiple RCTs, AChEIs displayed effectiveness in alleviating cognitive impairment associated with MCI, but only temporarily with some adverse effects. Given the difficulty in determining a clear use of AChEIs on slowing the progression of MCI, additional research is needed. Non-pharmacological interventions have also displayed effectiveness without risk of adverse drug effects. Literature regarding multimodal approaches combining both pharmacological and non-pharmacological interventions is a novel area of research, and these studies have suggested positive additive effects.

Conclusion: Pharmacological and non-pharmacological interventions for slowing the progression of MCI display promising results. More studies are needed to determine which treatment plans, whether pharmacological, non-pharmacological, or a combination of the two, will prove to be the most effective for individuals with MCI.
\end{abstract}

Keywords: mild cognitive impairment; dementia; Alzheimer's disease

\section{Introduction}

Mild cognitive impairment (MCI) is characterized by cognitive deficiencies beyond what is considered normal for a person's age $[1,2]$. These levels of cognitive impairments do not meet the criteria for dementia, since individuals with MCI are still able to perform daily tasks with little to no difficulty [3]. The significance of MCI lies in its potential to progress to various forms of dementia, most notably Alzheimer's disease (AD) $[2,4]$. AD is the most common neurodegenerative disease and has a remarkably slow clinical onset [5]. Importantly, by the time AD is diagnosed, irreversible neurodegeneration has likely occurred, leaving few treatment options for individuals with $\mathrm{AD}$ [5]. It is estimated that $10-54 \%$ of MCI diagnoses will develop into dementia per year, and 10-15\% will develop into AD [6]. This translates to the need for effective pharmacological and non-pharmacological treatments to prevent the progression of MCI and subsequently slow the onset of AD.

Current pharmacological treatments have shown potential in slowing the progression of MCI, most notably acetylcholinesterase (AChE) inhibitors. AChEIs have been widely used to treat symptoms associated with $\mathrm{AD}$, due to their ability to inhibit acetylcholine (ACh) degradation $[7,8]$. Low cholinergic function may be associated with the cognitive symptoms of AD [8]. Multiple cholinergic pathways within the brain play important roles in cognitive functions such as consciousness, working memory, and attention [9]. Individuals with $\mathrm{AD}$ have consistently shown damage to these cholinergic pathways, suggesting low ACh may be correlated with cognitive symptoms of $\mathrm{AD}$ [9]. This correlation indicates the potential protective role of AChEIs for MCI treatment, as these essential ACh pathways could be preserved [8]. Despite 
UNDERGRADUATE RESEARCH IN NATURAL AND CLINICAL SCIENCE AND TECHNOLOGY (URNCST) JOURNAL Read more URNCST Journal articles and submit your own today at: https://www.urncst.com

the potential benefit of AChEIs, adverse effects have been noted [10]. This highlights the importance of research in nonpharmacological interventions, since these alternative methods may prove to be valuable alternatives to traditional pharmacological approaches.

Recent research efforts have focused on nonpharmacological interventions towards slowing the progression of MCI. Age-dependent changes at the nutritional level have been thought to play a role in healthy brain functioning [11-13]. Certain nutrient deficiencies may exacerbate abnormal development in the aging brain [11]. Omega-3 (n-3) fatty acid (FA) supplementation and antioxidant administration have been explored as potential therapies for individuals with MCI. Docosahexaenoic acid (DHA) is an n-3 FA that plays an important role in neurotransmission, membrane fluidity, and reducing inflammation and oxidative stress $[14,15]$. These properties may preserve cognitive function, especially in clinical older adult populations [16].

Oxidative stress, specifically the presence of reactive oxygen species (ROS), plays an important role in heralding the presence of $\mathrm{AD}$ [17]. Oxidative stress has the ability to damage cells, specifically within mitochondria, in a way that will provide a continuous source of ROS [18]. This continuous source of ROS may play a role in mediating the progression of MCI to $\mathrm{AD}$ [17]. Another large area of research surrounds flavanols, a subclass of flavonoids that are proposed to increase neurocognitive performance by increasing the number and strength of connections in the brain [19]. Thus, flavanol-containing foods may be a possible non-pharmacological treatment for MCI.

Moreover, the integration of physical activity as a treatment has shown positive results in preventing neurodegeneration in the older adult population [20]. Not only is aerobic exercise beneficial to physical health, but it can also stimulate cognitive functions within the spectrum of dementia severity [21]. Certain types of physical activity may be even more valuable in terms of cognitive stimulation, including dance, which combines emotion, coordination, and acoustic stimulation [21]. Alternatively, a sedentary lifestyle may be linked to age-dependent cognitive decline, suggesting a beneficial role of physical exercise on cognitive functions in older adults with MCI [6]. However, this research remains preliminary; long-term studies are needed to substantiate the therapeutic effects of exercise therapy on MCI progression. Few studies have systematically investigated this with randomized controlled trials (RCTs).

Given the auspicious findings in the current literature, the purpose of this review paper is to discuss the effectiveness of pharmacological and non-pharmacological treatments in slowing the progression of MCI. In terms of pharmacological treatments, this review will analyze AChEIs. In terms of non-pharmacological treatments, this review will focus on lifestyle changes that can be easily integrated into a daily routine - specifically dietary changes and physical activity. To ensure the studies are well controlled and that cause-and-effect relationships can be explored, only RCTs were included in this review [22].

\section{Methods}

A literature search was conducted using the database PubMed. The keywords that were input into the search engine included ("mild cognitive impairment" AND "drug" AND "treatment", AND "randomized controlled trials"). As this review is focused on primary research, the word "systematic review" was removed from the literature search. All studies were limited to the years 2000 to 2021.

The two co-authors collaboratively judged the eligibility of the first 200 articles in the search. Articles were included based on their ability to meet the inclusion and exclusion criteria. Namely, articles were included if they displayed relevance to our review, and were excluded if they were not an RCT, lacked clear rationale, had comorbid participants, or if the study was conducted in a niche field with minimal supporting studies. Furthermore, studies were excluded if the participants were diagnosed with AD and not MCI. From this search, a total of three RCTs were relevant in the pharmacological section, and seven were relevant in the nonpharmacological section.

\section{Results}

Pharmacological

AChEIs have been demonstrated to be an effective pharmacological treatment in slowing the progression of MCI [23]. These medications act to increase the duration and concentration of ACh present in associated synapses, which is believed to alleviate cognitive decline in individuals with MCI [23].

Salloway et al. [24] investigated the usage of donepezil, an $\mathrm{AChE}$ inhibitor, in 270 individuals diagnosed with MCI. This was done through a double-blind RCT over 24 weeks. Although the primary measures (delayed recall test and semi-structured interviews) displayed no significant difference between donepezil and placebo groups, secondary measures (including AD assessment scale, naming task, verbal fluency test) showed promising efficacy of donepezil. Secondary measures included the Patient Global Assessment and a modified AD Assessment Scale (ADAS)-cognitive subscale, both displaying donepezil-treated patients to have increased scores and subsequently increased general cognition. A later study conducted by Montero-Odasso et al. [25] analyzed donepezil's efficacy in relation to motor function. A double-blind, placebo-controlled RCT was employed, and the main outcome of interest was dual-task gait cost (DTC). DTC is defined as the difference between gait speed (time to walk a certain distance) while performing a task and without performing a task. Individuals with MCI typically have a higher DTC, as they have difficulty performing a cognitive task while walking. After the study duration of six months, the donepezil group showed a significant reduction in DTC. 
UNDERGRADUATE RESEARCH IN NATURAL AND CLINICAL SCIENCE AND TECHNOLOGY (URNCST) JOURNAL Read more URNCST Journal articles and submit your own today at: https://www.urncst.com

Petersen et al. [26] performed an RCT testing donepezil as a treatment option for slowing the progression of MCI. Their measures included the Clinical Dementia Rating (CDR), Mini Mental State Examination (MMSE), and ADAS-cognitive subscale. Their three-year study found donepezil treatment to slow the progression of MCI for the first 12 months of use compared to the placebo group. However, after the entire study duration, there was no significant difference in the likelihood of developing $A D$ between the two groups.

\section{Diet Supplementation}

Nutritional changes associated with aging have been thought to play a role in healthy brain functioning [11-13]. Certain nutrient deficiencies may exacerbate abnormal development in the aging brain [11]. Recent research has been interested in the potential beneficial effects of dietary supplements in slowing the progression of MCI. One focus is on n-3 FA supplementation, which extends previous studies linking n-3 FA to reduced cases of dementia [12]. In the context of MCI, Lee et al. studied the efficacy of fish oil (an n-3 FA) supplementation on cognitive function in this population [13]. A 12-month double-blind, placebocontrolled RCT was conducted using the n-3 FA DHA. Compared to the control group, the intervention group showed significant improvement in short-term memory and working memory. This suggests daily fish oil supplementation can be an effective non-pharmacological supplement to alleviate cognitive impairment. These results are paralleled in Rondanelli et al. examining the role of nutritional supplementation in preventing or delaying cognitive impairment [11]. This 12-week double-blind, placebo-controlled RCT was conducted with older adults diagnosed with $\mathrm{MCI}$. The experimental group supplemented with DHA displayed improvements on multiple cognitive domains compared to the control group.

Dietary flavanols and their antioxidant properties have been closely associated with improving cognitive function in older adults with MCI [19]. Commonly found in grapes and cocoa products, flavanols have shown efficacy in reversing age-dependent neurocognitive decline [19]. In a study by Desideri et al., 90 participants diagnosed with MCI underwent an eight-week double-blind RCT [19]. Participants were randomly assigned to consume a drink containing varying levels of cocoa flavanols (CFs). Four standardized tests were utilized: the MMSE, Trail Making Test (TMT) A (to measure processing speed), TMT B (to measure executive function), and a verbal fluency test (VFT). This study found improved cognitive performance with cocoa flavanol consumption, in addition to other health benefits such as reduced blood pressure. Significant improvements were observed in all the cognitive domains measured, even with low levels of flavanol consumption. These findings are consistent with Mastroiacovo et al. [27], which also provided evidence that dietary intervention through regular $\mathrm{CF}$ consumption can delay age-related cognitive decline. Using the same four cognitive assessments in an eight-week double-blind RCT, participants were instructed to either maintain their usual intake of fruits and vegetables (control group), or to avoid the intake of flavanolcontaining foods (experimental group). The control group showed improvements in cognitive performance over the experimental group that had diets deprived of flavanol.

\section{Exercise}

Exercise has shown promising results in slowing the progression of $\mathrm{MCI}$ and improving cognitive function $[20,28,29]$. An RCT by Tsai et al. [28] examined how acute instances of aerobic training and resistance training affect biomarkers of MCI. The study examined certain neuroprotective growth factors, such as brain-derived neurotrophic factor (BDNF) and insulin-like growth factor 1 (IGF-1) as biomarkers indicating a lower risk for MCI progression. These growth factors are at lower levels in individuals with $\mathrm{AD}$ compared to those with slower cognitive decline. They found acute aerobic activity to increase BDNF and IGF-1 levels, and resistance exercise training to increase IGF-1 levels.

Usage of rhythm-based exercise demonstrated increased cognitive function amongst those with $\mathrm{MCI}$ as well. A study conducted by Lazarou et al. [20] analyzed the usage of ballroom dancing as a treatment for cognitive decline in 154 participants with MCI [20]. The intervention group underwent two dance classes per week for 10 months. Compared to the control group, which displayed a decline in cognitive function, the intervention group demonstrated a significant increase in cognitive function, as assessed by multiple neuropsychological tests, such as MMSE and TMT B. Furthermore, Shimizu et al. [29] examined the effect of music movement therapy (MMT) on individuals with MCI. The experimental groups underwent MMT over a 14-week period and subsequently demonstrated increased medial prefrontal cortex activity compared to controls.

\section{Discussion}

This review summarizes the effectiveness of current pharmacological and emerging non-pharmacological therapies in treating the progression of MCI. The most prevalent pharmacological treatments observed in the literature search were AChEIs, whereas common nonpharmacological treatments included diet supplementations and exercise interventions.

\section{Traditional Pharmacological Treatments for MCI}

Studies by Salloway et al. and Montero-Odasso et al. demonstrated the effectiveness of donepezil in preventing the progression of MCI $[24,25]$. AChEIs can increase ACh levels in the central nervous system to combat ACh deficiency found in individuals with MCI [23]. Salloway et al. showed this increase in ACh may help improve cognitive function, while Montero-Odasso et al. suggested this mechanism may additionally help motor function pathways 
UNDERGRADUATE RESEARCH IN NATURAL AND CLINICAL SCIENCE AND TECHNOLOGY (URNCST) JOURNAL Read more URNCST Journal articles and submit your own today at: https://www.urncst.com

[24,25]. Given these findings, AChEIs are currently regarded as a frequently prescribed drug in individuals with MCI [30]. However, they may not be a viable standalone treatment.

In a review on pharmacotherapies surrounding MCI, Gauthier suggests that AChEIs have an effect on the symptomatic aspect of MCI, but do not delay its progression past the initial 18 months of use [31]. Furthermore, AChEIs have adverse effects ranging from gastrointestinal issues to abnormal dreams, and therefore may not be suitable for everybody [31]. Literature including Petersen et al. supports the hypothesis that AChEIs work in the short term, but not the long term [26].

Due to the difficulty in establishing effectiveness in slowing the progression of MCI in the long term versus simply treating its symptoms over the short term, alternative methods to AChEIs should be studied.

\section{Novel Non-Pharmacological Interventions for MCI}

The potential efficacy of non-pharmacological therapies was demonstrated in the studies aforementioned. In the studies examining the effects of n-3 FA supplementation, both findings illustrated a positive effect in age-related cognitive maintenance [11,13]. Similarly, experimental groups with consistent intake of flavanols exhibited healthy cognitive aging, which suggests its ability to reverse cognitive decline in normal aging $[19,27]$. Exercise has shown to increase neuroprotective factors, which preserve cognitive function to a higher degree than without, which may slow the progression of MCI [28]. Furthermore, MMT has the ability to preserve cognitive function and subsequently slow the progression of MCI [20,29].

Non-pharmacological treatments may be more universally applicable, as they provide an option for individuals who experience or seek to avoid the side effects associated with pharmacological options [32]. Furthermore, the majority of non-pharmacological interventions are unlikely to counteract drug therapies [32]. These reasons highlight the benefits of utilizing a treatment that involves exercise or diet changes.

Despite the benefits of applying non-pharmacological treatment plans, some limitations exist. Studies on nonpharmacological interventions are still emerging, thus, only a small body of evidence supports their widespread use. Though studies in this review demonstrated their effectiveness in treating MCI, multiple articles claim a much less definitive result $[26,33]$. There is a need for more RCTs investigating the effectiveness of emerging nonpharmacological interventions, such as n-3 fatty acid supplementation, flavanol supplementation, and exercise.

\section{Multimodal Approaches}

The discussion around multimodal approaches in treating MCI lies in the effectiveness of combining pharmacological and non-pharmacological treatments. Researchers can consider the potential additive benefits these treatments have if they were taken in conjunction with one another. In fact, studies comparing singular treatment methods to multimodal interventions found higher cognitive performance in the latter [34]. Previous research suggests multimodal approaches may increase the effect of each individual intervention and therefore have positive additive effects on brain function [34]. However, a disparity in literature exists regarding the effects of combining cognitive stimulation, nutritional supplementation, and physical activity, especially in human participants [34]. Kobe et al. [34] suggested combining different treatment methods may exceed the benefits that would otherwise be observed in only a single treatment method. This study was one of the first of its kind to demonstrate that $\mathrm{n}-3$ supplementation combined with aerobic exercise and cognitive stimulation can significantly reduce atrophy in susceptible brain regions in individuals with MCI (i.e. hippocampus, frontal regions, and cingulate cortex). Results further found combined interventions can pose additive or even "superadditive" effects on brain structure and function, which can significantly reduce the rate of atrophy in grey matter regions.

\section{Future Directions and Limitations}

Much of the current literature revolves around treatment from a pharmacological perspective. The future of nonpharmacological treatments of MCI is an emerging field of research that is gaining traction as studies continue to be conducted. This was observed in the literature with the few articles that investigated MCI treatments from a multimodal approach. At the time, Kobe et al. [34] found no other published studies investigating the effects of n-3 FAs on the brain structure in participants with MCI. This emphasizes the novelty in this field of research and translates to a need for more studies.

Additionally, promising non-pharmacological treatments have been demonstrated in animal models but have yet to be established in human studies. For example, Mangifera indica, or mango fruit, has been found to contain medicinal properties that provide beneficial effects on oxidative stress [35]. Wattanathorn et al. [35] studied the effects of $M$. indica on rats with memory deficits, and found a decrease in oxidative stress, suggesting an increase in memory performance and cholinergic neuron density in the brain. Despite these promising findings, this study is an example of a research field that is yet to be investigated in humans. Overall, more RCTs and long-term studies are needed to demonstrate the effectiveness of both emerging non-pharmacological treatments and multimodal approaches.

Limitations of this review included the strict inclusion criteria, which narrowed our sample size. Limiting the review to only RCTs resulted in difficulty when analyzing the long-term effects of MCI treatment. Including longitudinal studies in the criteria may have been more comprehensive, as these studies may provide information on MCI progression over an extended period. Furthermore, the use of a singular database and its first 200 articles limited the 
UNDERGRADUATE RESEARCH IN NATURAL AND CLINICAL SCIENCE AND TECHNOLOGY (URNCST) JOURNAL Read more URNCST Journal articles and submit your own today at: https://www.urncst.com

comprehensiveness of this review. The first 200 articles were selected in order of relevancy, based on their compatibility with the keywords.

\section{Conclusions}

Much evidence supports the usage of both pharmacological and non-pharmacological treatments in slowing the progression of MCI. Decreased ACh levels are commonly observed among individuals with MCI, which translates to AChEIs being a commonly prescribed pharmacological treatment [9,31]. Despite their popularity for treating short-term symptoms, their effectiveness in slowing the long-term progression into greater degrees of dementia is not well established. Future research should continue to investigate the most effective pharmacological treatment for slowing MCI progression. Additionally, emerging non-pharmacological interventions for MCI show promise, but also remain unclear. Diet supplementation and physical activity have shown efficacy in mediating agerelated changes in those with $\mathrm{MCI}$, but further studies are still needed to determine long-term advantages [1113,20,28,29]. RCTs and long-term studies will continue to be valuable in establishing effective treatments in slowing the progression of MCI.

\author{
List of Abbreviations Used \\ AD: Alzheimer's disease \\ RCT: randomized controlled trial \\ AChEIs: acetylcholinesterase inhibitors \\ MCI: mild cognitive impairment \\ ACh: acetylcholine \\ n-3: omega-3 \\ FA: fatty acid \\ DHA: docosahexaenoic acid \\ ROS: reactive oxygen species \\ ADAS: AD assessment scale \\ DTC: dual-task gait cost \\ CDR: clinical dementia rating \\ MMSE: mini mental state examination \\ CF: cocoa flavanol \\ TMT: trail making test \\ VFT: verbal fluency test \\ BDNF: brain-derived neurotrophic factor \\ IGF-1: insulin-like growth factor 1 \\ MMT: music movement therapy
}

\section{Conflicts of Interest}

The authors declare that they have no conflict of interest.

\section{Ethics Approval and/or Participant Consent}

This literature review did not require ethics approval and/or participation consent. All literature included in this review had previous ethics approval in their respective studies.

\section{Authors' Contributions}

PT: made contributions to the design of the study, collected and analyzed data, drafted the manuscript, and gave final approval of the version to be published.

DY: made contributions to the design of the study, collected and analyzed data, drafted the manuscript, and gave final approval of the version to be published.

\section{Acknowledgements}

The authors would like to thank their mentor, Ricky Chow, for his continuous support and active guidance throughout the entire writing process.

\section{Funding}

This study was not funded.

\section{References}

[1] Langa KM, Levine DA. The diagnosis and management of mild cognitive impairment: A clinical review. JAMA. 2014;312(23):2551-61. https://doi.org/10.1001/jama.2014.13806

[2] Karakaya T, Fußer F, Schroder J, Pantel J. Pharmacological treatment of mild cognitive impairment as a prodromal syndrome of Alzheimer's disease. Current Neuropharmacology. 2013;11(1):1028. https://doi.org/10.2174/157015913804999487

[3] Winblad B, Palmer K, Kivipelto M, Jelic V, Fratiglioni L, Wahlund LO, et al. Mild cognitive impairmentBeyond controversies, towards a consensus: Report of the international working group on mild cognitive impairment. Journal of Internal Medicine. 2004;256(3):240-6. https://doi.org/10.1111/j.13652796.2004.01380.x

[4] Rodakowski J, Reynolds III CF, Lopez OL, Butters MA, Dew MA, Skidmore ER. Developing a nonpharmacological intervention for individuals with mild cognitive impairment. Journal of Applied Gerontology. 2016;37(5):665-76. https://doi.org/10.1177/0733464816645808

[5] Rosenberg PB, Lyketsos C. Mild cognitive impairment: Searching for the prodrome of Alzheimer's disease. World Psychiatry. 2008;7(2):72-8. https://doi.org/10.1002/j.2051-5545.2008.tb00159.x

[6] Kimura K, Yasunaga A, Wang LQ. Correlation between moderate daily physical activity and neurocognitive variability in healthy elderly people. Archives of Gerontology and Geriatrics. 2013;56(1): 109-17. https://doi.org/10.1016/j.archger.2012.10.004

[7] Wilcock GK, Lilienfeld S, Gaens E. Efficacy and safety of galantamine in patients with mild to moderate Alzheimer's disease: Multicentre randomized controlled trial. BMJ. 2000;321(7274):1445. https://doi.org/ $\underline{10.1136 / \mathrm{bmj} .321 .7274 .1445}$ 
UNDERGRADUATE RESEARCH IN NATURAL AND CLINICAL SCIENCE AND TECHNOLOGY (URNCST) JOURNAL Read more URNCST Journal articles and submit your own today at: https://www.urncst.com

[8] Tabet N. Acetylcholinesterase inhibitors for Alzheimer's disease: Anti-inflammatories in acetylcholine clothing! Age and Ageing. 2006;35(4):336-8. https://doi.org/ 10.1093/ageing/afl027

[9] Terry AV, Buccafusco JJ. The cholinergic hypothesis of age and Alzheimer's disease-related cognitive deficits: Recent challenges and their implications for novel drug development. Journal of Pharmacology and Experimental Therapeutics. 2003;306(3):821-7. https://doi.org/10.1124/jpet.102.041616

[10] Inglis F. The tolerability and safety of cholinesterase inhibitors in the treatment of dementia. International Journal of Clinical Practice. Supplement. 2002;(127): 45-63. Available from: https://pubmed.ncbi.nlm.nih.gov/12139367/

[11] Rondanelli M, Opizzi A, Faliva M, Mozzoni M, Antoniello N, Cazzola R, et al. Effects of a diet integration with an oily emulsion of DHAphospholipids containing melatonin and tryptophan in elderly patients suffering from mild cognitive impairment. Nutritional Neuroscience. 2012;15(2):4654. https://doi.org/10.1179/1476830511Y.0000000032

[12] Sonobe N, Hata R, Ishikawa T, Sonobe K, Matsumoto T, Toyota Y, Mori T, Fukuhara R, Komori K, Ueno SI, Tanimukai S. Risk of progression from mild memory impairment to clinically diagnosable Alzheimer's disease in a Japanese community (from the Nakayama study). International Psychogeriatrics. 2011;23(5):7729. https://doi.org/10.1017/S104161021000222X

[13] Lee LK, Shahar S, Chin AV, Yusoff NA. Docosahexaenoic acid-concentrated fish oil supplementation in subjects with mild cognitive impairment (MCI): A 12-month randomised, doubleblind, placebo-controlled trial. Psychopharmacology. 2013;225(3):605-12. https://doi.org/10.1007/s00213012-2848-0

[14] Pomponi M, Pomponi M. DHA deficiency and Alzheimer's disease. Clinical Nutrition. 2008;27(1): 170. https://doi.org/10.1016/j.clnu.2007.10.009

[15] Cunnane SC, Plourde M, Pifferi F, Bégin M, Féart C, Barberger-Gateau P. Fish. Docosahexaenoic acid and Alzheimer's disease. Progress in Lipid Research. 2009;48(5):239-56. https://doi.org/10.1016/j.plipres.2009 .04 .001

[16] Fontani G, Corradeschi F, Felici A, Alfatti F, Migliorini S, Lodi L. Cognitive and physiological effects of Omega-3 polyunsaturated fatty acid supplementation in healthy subjects. European Journal of Clinical Investigation. 2005;35(11):691-9. https://doi.org/10.1111/j.1365-2362.2005.01570.x

[17] Mecocci P, Mariani E, Cornacchiola V, Polidori MC. Antioxidants for the treatment of mild cognitive impairment. Neurological Research. 2004;26(5):598602. https://doi.org/10.1179/016164104225017659
[18] Vásquez-Vivar J, Kalyanaraman B, Kennedy MC. Mitochondrial aconitase is a source of hydroxyl radical: An electron spin resonance investigation. Journal of Biological Chemistry. 2000;275(19):14064-9. https://doi.org/10.1074/jbc.275.19.14064

[19] Desideri G, Kwik-Uribe C, Grassi D, Necozione S, Ghiadoni L, Mastroiacovo D, et al. Benefits in cognitive function, blood pressure, and insulin resistance through cocoa flavanol consumption in elderly subjects with mild cognitive impairment: The cocoa, cognition, and aging (CoCoA) study. Hypertension. 2012;60(3):794-801. https://doi.org/ 10.1161/HYPERTENSIONAHA

[20] Lazarou I, Parastatidis T, Tsolaki A, Gkioka M, Karakostas A, Douka S, et al. International ballroom dancing against neurodegeneration: A randomized controlled trial in Greek community-dwelling elders with mild cognitive impairment. American Journal of Alzheimer's Disease \& Other Dementias. 2017;32(8):489-99. https://doi.org/10.1177/1533317 517725813

[21] Brown S, Martinez MJ, Parsons LM. The neural basis of human dance. Cerebral Cortex. 2006;16(8):1157-67. https://doi.org/10.1093/cercor/bhj057

[22] Hariton E, Locascio JJ. Randomised controlled trialsThe gold standard for effectiveness research. BJOG: An International Journal of Obstetrics and Gynecology. 2018;125(13):1716. https://doi.org/10.1111/1471-0528 .15199

[23] Colovic MB, Krstic DZ, Lazarevic-Pasti TD, Bondzic AM, Vasic VM. Acetylcholinesterase inhibitors: Pharmacology and toxicology. Current Neuropharmacology. 2013;11(3):315-35. https://doi.org/ 10.2174/1570159X11311030006

[24] Salloway S, Ferris S, Kluger A, Goldman R, Griesing T, Kumar D, et al. Efficacy of donepezil in mild cognitive impairment: A randomized placebocontrolled trial. Neurology. 2004;63(4):651-7. https://doi.org/10.1212/01.wnl.0000134664.80320.92

[25] Montero-Odasso M, Speechley M, Chertkow H, Sarquis-Adamson Y, Wells J, Borrie M, et al. Donepezil for gait and falls in mild cognitive impairment: A randomized controlled trial. European Journal of Neurology. 2019;26(4):651-9. https://doi.org/10.1111/ene.13872

[26] Petersen RC, Thomas RG, Grundman M. Donepezil and vitamin $\mathrm{E}$ for mild cognitive impairment. Current Psychiatry Reports. 2006;8(1):9. https://doi.org/10.1056/ NEJMoa050151 
UNDERGRADUATE RESEARCH IN NATURAL AND CLINICAL SCIENCE AND TECHNOLOGY (URNCST) JOURNAL Read more URNCST Journal articles and submit your own today at: https://www.urncst.com

[27] Mastroiacovo D, Kwik-Uribe C, Grassi D, Necozione S, Raffaele A, Pistacchio L, et al. Cocoa flavanol consumption improves cognitive function, blood pressure control, and metabolic profile in elderly subjects: The cocoa, cognition, and aging ( $\mathrm{CoCoA})$ study - A randomized controlled trial. The American Journal of Clinical Nutrition. 2015;101(3):538-48. https://doi.org/10.3945/ajen.114.092189

[28] Tsai CL, Ukropec J, Ukropcová B, Pai MC. An acute bout of aerobic or strength exercise specifically modifies circulating exerkine levels and neurocognitive functions in elderly individuals with mild cognitive impairment. NeuroImage: Clinical. 2018;17:272-84. https://doi.org/10.1016/j.nicl.2017.10.028

[29] Shimizu N, Umemura T, Matsunaga M, Hirai T. Effects of movement music therapy with a percussion instrument on physical and frontal lobe function in older adults with mild cognitive impairment: A randomized controlled trial. Aging \& Mental Health. 2018;22(12):1614-26. https://doi.org/10.1080/13607863 .2017 .1379048

[30] Han JY, Besser LM, Xiong C, Kukull WA, Morris JC. Cholinesterase inhibitors may not benefit mild cognitive impairment and mild Alzheimer disease dementia. Alzheimer Disease and Associated Disorders. 2019;33(2):87. https://doi.org/10.1097/ WAD.0000000000000291
[31] Gauthier S. Pharmacotherapy of mild cognitive impairment. Dialogues in Clinical Neuroscience. 2004;6(4):391. https://doi.org/10.31887/DCNS.2004.6.4/ sgauthier

[32] Rodakowski J, Saghafi E, Butters MA, Skidmore ER. Non-pharmacological interventions for adults with mild cognitive impairment and early stage dementia: An updated scoping review. Molecular Aspects of Medicine. 2015;43:38-53. https://doi.org/10.1016/ j.mam.2015.06.003

[33] Cooper C, Li R, Lyketsos C, Livingston G. Treatment for mild cognitive impairment: Systematic review. The British Journal of Psychiatry. 2013;203(4):255-64. https://doi.org/10.1192/bjp.bp.113.127811

[34] Köbe T, Witte AV, Schnelle A, Lesemann A, Fabian S, Tesky VA, Pantel J, Flöel A. Combined omega-3 fatty acids, aerobic exercise and cognitive stimulation prevents decline in gray matter volume of the frontal, parietal and cingulate cortex in patients with mild cognitive impairment. Neuroimage. 2016 May 1;131:226-38. https://doi.org/10.1016/j.neuroimage .2015 .09 .050

[35] Wattanathorn J, Muchimapura S, Thukham-Mee W, Ingkaninan K, Wittaya-Areekul S. Mangifera indica fruit extract improves memory impairment, cholinergic dysfunction, and oxidative stress damage in animal model of mild cognitive impairment. Oxidative Medicine and Cellular Longevity. 2014 Jan 29;2014. https://doi.org/https://doi.org/10.1155/2014/132097

\section{Article Information}

Managing Editor: Jeremy Y. Ng

Peer Reviewers: Ricky Chow, Jala Rizq

Article Dates: Received Aug 07 21; Accepted Sep 16 21; Published Oct 2121

\section{Citation}

Please cite this article as follows:

Thum P, Ye D. Current pharmacological and emerging non-pharmacological treatments in slowing the progression of mild cognitive impairment: A literature review. URNCST Journal. 2021 Oct 21:5(10).

https://urncst.com/index.php/urncst/article/view/312

DOI Link: https://doi.org/10.26685/urncst.312

\section{Copyright}

(C) Phoebe Thum, Damon Ye. (2021). Published first in the Undergraduate Research in Natural and Clinical Science and Technology (URNCST) Journal. This is an open access article distributed under the terms of the Creative Commons Attribution License (https://creativecommons.org/licenses/by/4.0/), which permits unrestricted use, distribution, and reproduction in any medium, provided the original work, first published in the Undergraduate Research in Natural and Clinical Science and Technology (URNCST) Journal, is properly cited. The complete bibliographic information, a link to the original publication on http://www.urncst.com, as well as this copyright and license information must be included. 


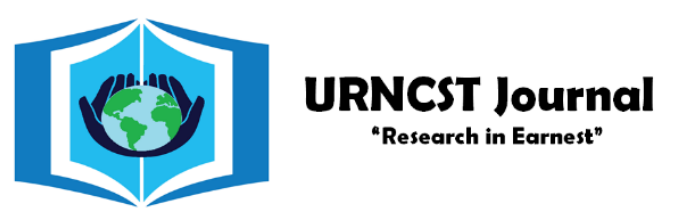

\section{Funded by the Government of Canada}

\section{Canadà̀}

Do you research in earnest? Submit your next undergraduate research article to the URNCST Journal!

| Open Access | Peer-Reviewed | Rapid Turnaround Time | International |

| Broad and Multidisciplinary | Indexed | Innovative | Social Media Promoted |

Pre-submission inquiries? Send us an email at info@ urncst.com | Facebook, Twitter and LinkedIn: @URNCST

Submit YOUR manuscript today at https://www.urncst.com! 